\title{
The influence of socio-economic factors on uptake of rhizobia inoculant technology in the northern
} region

\begin{abstract}
This study principally assessed the influence of socio-economic factors on uptake of rhizobia inoculant technology in the Northern Region. Sample sizes of 210 respondents were interviewed using questionnaires. Secondary data was also collected for the study and the results analyzed. Simple random and purposive sampling techniques were used in selecting respondents. The data were analyzed using appropriate descriptive statistics and multiple linear regressions. The linear multiple regression model was fitted to estimate the factors that are perceived to influence or predicts farmers Uptake of Rhizobia inoculant. The adjusted coefficient of determination (R2) of 0.350 suggests that, $35.0 \%$ of the variation of farmers' uptake of rhizobia inoculant can be explained by the model. On the other hand, the linear regression model revealed nine variables had significantly influence on farmers' uptake of rhizobia inoculant in the study area, these includes; Years of inoculant introduction, Sex, Demonstration plot, Age, Video show, Marital Status, Farm size, Farming Experience, Radio program and Educational level at $5.0 \%$ significant level.
\end{abstract}

Keywords: uptake, rhizobia inoculant, socio-economic factors
Volume 2 Issue 6 - 2018

\author{
Samuel Safo K Allotey, Paul Kwami Adraki \\ Department of Agricultural Extension, University for \\ Development Studies, Ghana
}

Correspondence: Samuel Safo K Allotey, Department of Agricultural Extension, Rural Development and Gender Studies, University for Development Studies, Tamale, Ghana, Email alloteysamuel@yahoo.com

Received: April 07, 2018| Published: November 15, 2018

\section{Introduction}

The agricultural sector faces a challenge of poor soil fertility and food insecurity in Africa, ${ }^{1}$ with high cost of inorganic fertilizer ${ }^{2}$ and poor economic status of most smallholder farmers. Farmers in Africa are unable to inorganic fertility, agricultural research have developed rhizobia inoculants as a cost effective substitute of improving low soil fertility, ${ }^{3}$ as well as boosting yield of soybeans. ${ }^{4}$

However, the use of rhizobium inoculants have been an effective agronomic practice for ensuring adequate $\mathrm{N}$-nutrition of legumes, compared with the application of $\mathrm{N}$-fertilizer. ${ }^{5}$

The use of rhizobia inoculant boosts legumes production and improves soil fertility at a cheaper cost,${ }^{6}$ Notwithstanding its potential to addressing low Nitrogen in soil and its cost effectiveness, adoption of rhizobia inoculants by farmers still remains low. ${ }^{7}$ Whiles, the country is still far from realizing wide-scale use of rhizobia inoculant among farmers. To achieve realized wide-scale use of rhizobia inoculant among farmers, it would be important to understand the factors which influence uptake or adoption of agricultural technology among end users. However, leading researchers have established a relationship between socio-economic characteristics and technology adoption. For instance, Lavison ${ }^{8}$ established that farm size can affect and in turn be affected by the other factors influencing of technology adoption. Also, human capital of the farmer is assumed to have a significant influence on farmers' decision to adopt new technologies, ${ }^{9}$ Education of the farmer has been noted to have a positive influence on farmers' decision to adopt new technology. Education level of a farmer increases his/her ability to obtain; process and use information relevant to adoption of a new technology. ${ }^{8,10}$
Age is seen as another determinant of adoption of innovation. With older farmers assumed to have gained knowledge and experience over time and are better able to evaluate technology information than younger farmers. ${ }^{11}$ Bonabana \&Wabbi, ${ }^{12}$ suggested that sex is a determinant of agricultural technology adoption. Since the head of most farming household is the primary decision maker and men have more access to and control over important production resources than women because of socio-cultural values and norms. ${ }^{10}$

Thus, all these scholars' points to the fact that farmers' socioeconomics factors have influence on uptake of technology. Hence, this paper aims to determine how farmers' socio-economics factors would influence uptake of rhizobia inoculant technology in the Northern Region by examining its effects with respect to farmers intensity to use rhizobia inoculant technology in farms and draw conclusions that might help in developing interventions to encourage adoption of rhizobia inoculant technology

\section{Methodology}

The study will be carried out in the northern region of Ghana. Primary data on socio-economic factors that influence farmers' uptake of rhizobia inoculant technology in the Northern Region were collected using questionnaire and key informant interviews (among legume farmers) to 210 respondents. Secondary data were gathered from records of SARI, IITA as well as reviews of journals and library materials. The survey employed purposive and simple random sampling techniques in selecting the sample for the study, in selecting the districts for the study, purposive sampling technique were employed and two (2) districts out of 27 districts in the Northern Region were selected. These districts were, namely Tolon District and Savelugu Municipality. 
The selection is because of the operations of Savannah Agricultural Research Institutes (SARI) and International Institute of Tropical Agriculture (IITA) within these districts having major demonstrations field and community outreach. Six communities were randomly selected from Savelugu Municipality and Tolon district respectively. From the list of legume farmers from each community sampled, the lottery method of random sampling technique were used to sample 35 legume farmers from each of the six communities to form a sample size of 210 in the Northern Region of Ghana. Data was analysed using frequencies and percentage as well as multiples linear regression.

\section{Results and discussion \\ Demographic profile of farmers}

The survey results (Table 1) show that majority of legume farmers (73.3 \%) were males; with 26.7 percent of legume farmers being females. Although females form the least group in the survey, they play several roles such as planting, harvesting, shelling of legumes etc. However, much of what the women do on the farm is, mostly considered as family labour and this could accounts for the small number of female farmers $(26.7 \%)$ in the study area. On age of respondents, the results revealed that, 23.8 percent of the farmers were below the age 30 , with 5.7 percent being above 60 years. However, 37.6 percent of farmers were between 30 and 45 years, whiles $32.9 \%$ of the respondents were between the age 46 and 60 (table 1.0) as seen the table below. The analysis on marital status of respondents indicates that, majority of farmers $(78.1 \%)$ interviewed were married, while very few $(5.2 \%)$ are single (never married) and 10 percent and 6.7 percent divorcees and windows respectively. With educational status of respondents, few farmers had Junior High education (9.0\%), primary education were 25.2 percent and 12.4 percent had secondary education. However, 53.3 percent had no-formal education. With, none of the respondent having tertiary. These results indicate that majority of the farmers were illiterates with no formal education. Though, Higher education status of a farmer increases their ability to process and use information disseminated to them on agricultural innovation. ${ }^{8}$

However, in line with the findings, it might be difficult for illiterate's farmers to properly understand information disseminated to them by promoters of rhizobium inoculant in order to make proper judgment on whether to adopt or not. With regard to farming experience, the results shows that, 19.5 percent of the respondents had less than 5 years' experience of legume production, with $28.1 \%$ had between 5-10 years' experience of legume production and 52.4 percent had more than 10 years' experience of legume production. Some researchers suggest that experience in a particular is relevant in achieving results over time, (Fiedler, 2007; McCall et al. 2004). Thus, this suggests that since, most legume farmers had a much farming experience in legume production, adoption of rhizobium inoculant is likely to occur after these projects are over.

\section{Relationship between farmers uptake rhizobia inoculant and socio-economic factors}

Table 1.9 demonstrates that Adjusted R Square for this model is 0.350 which indicates $35.0 \%$ of the variation on uptake of rhizobia inoculant (dependent variable), uptake of rhizobia inoculant (dependent variable) can be explained by Years of inoculant introduction, Sex, Demonstration plot, Age, Video show, Marital Status, Farm size, Farming Experience, Radio program and Educational level (independent variables) (Table 2).

\section{ANOVA analysis}

According to Table 1.10, the F-value of 12.243 is highly significant at 5\%. This indicates that the overall regression model with these independent variables (Years of inoculant introduction, Sex, Demonstration plot, Age, Video show, Marital Status, Farm size, Farming Experience, Radio program and Educational level) can well explain the variation of the dependent variable (Uptake of Rhizobia inoculant) (Table 3).

Table I Demographic Profile of Farmers.

\begin{tabular}{lll}
\hline Characteristics & $\begin{array}{l}\text { Farmers } \\
\text { frequency }\end{array}$ & Percentage \\
\hline Gender: & 154 & 73.3 \\
Male & 56 & 26.7 \\
Female & & \\
Age: & 50 & 23.8 \\
Below 30 & 79 & 37.6 \\
30-45 & 69 & 32.9 \\
46-60 & 12 & 5.7 \\
Above 60 & & \\
Marital Status: & 164 & 78.1 \\
Married & 11 & 5.2 \\
Single & 21 & 10.0 \\
Divorced & 14 & 6.7 \\
Widowed & & \\
Educational level: & 112 & 53.3 \\
No education & 53 & 25.2 \\
Primary school & 19 & 9.0 \\
Junior high school & 26 & 12.4 \\
Secondary/vocational institute & 26 \\
Farming Experience: & & \\
Less than 5 years ago & 41 & 19.5 \\
5-10 years ago & 59 & 28.1 \\
More than 10 years ago & 110 & 52.4 \\
Total & $\mathbf{2 1 0}$ & $\mathbf{1 0 0 . 0}$ \\
\hline
\end{tabular}

Source Field Survey Data, 2017

Table 2 Model Summary.

\begin{tabular}{llll}
\hline $\mathbf{R}$ & R square & Adjusted R square & $\begin{array}{l}\text { Std. error of the } \\
\text { estimate }\end{array}$ \\
\hline .617 & .381 & .350 & .400 \\
\hline
\end{tabular}

a. Predictors: (Constant), Years of inoculant introduction, Sex, Demonstration plot, Age, Video show, Marital Status, Farm size, Farming Experience, Radio program and Educational level

b. Dependent Variable: Uptake of Rhizobia inoculant

Source: Field Survey Data, 2017

\section{Relationship between farmers uptake rhizobia inoculant and socio-economic factors}

An equation is formed based on Table 1.11 below to determine the statistical significance of each of the independent variables (Years of inoculant introduction, Sex, Demonstration plot, Age, Video show, Marital Status, Farm size, Farming Experience, Radio program and Educational level) on the dependent variable (Uptake of Rhizobia inoculant). A linear multiple regression model was fitted to estimate 
the factors that are perceived to influence or predicts farmers Uptake of Rhizobia inoculant. The adjusted coefficient of determination $\left(\mathrm{R}^{2}\right)$ of 0.350 suggests that, $35.0 \%$ of the variation of farmers' uptake of rhizobia inoculant can be explained by the model. The result from the linear regression model revealed nine variables had significantly influence on farmers' uptake of rhizobia inoculant in the study area, which are Years of inoculant introduction, Sex, Demonstration plot, Age, Video show, Marital Status, Farm size, Farming Experience, Radio program and Educational level at 5.0\% significant level.

Table 3 ANOVA Analysis.

\begin{tabular}{llllll}
\hline Model & $\begin{array}{l}\text { Sum of } \\
\text { squares }\end{array}$ & Df & Mean square & F & Sig. \\
& & & & & \\
& & & & & \\
& 19.589 & 10 & 1.956 & 12.243 & .000 \\
$\begin{array}{l}\text { Regression } \\
\text { Residual }\end{array}$ & 31.840 & 199 & .160 & & \\
Total & 51.429 & 209 & & &
\end{tabular}

Source Field Survey Data, 2017

a. Predictors: (Constant), years of inoculant introduction, sex, demonstration plot, age, cideo show, marital status, farm size, farming experience, radio program and educational level

b. Dependent variable: uptake of rhizobia inoculants

\section{Sex}

Sex of respondents in the study area was found to have a positive effect on inoculant use with a coefficient of 0.233 . This means that women had a higher probability of inoculant use as compared to their male counterparts. Thus, women have a 0.233 higher chance of inoculant use compared to their male counterparts. This finding is in line with Obisesan (2014), studies which revealed a positive influence of sex on technology adoption.

\section{Age}

Age of respondents in the study area was found to have positive influence on the intensity of inoculant uptake with a coefficient of 0.309 . This implies that when age increases by one year, the probability that a farmer uses soybean inoculant increase by 0.309 keeping all things constant. This result confirms with Kariyasa and Dewi (2011), that age is a determinant of adoption of new technology. Older farmers are assumed to have gained knowledge and experience over time and are better able to evaluate technology information than younger farmers.

\section{Marital status}

The study revealed a negative relationship between marital status and uptake of rhizobia inoculant in the study area, with a coefficient of 0.291 . This implies that unmarried farmers are more likely to use rhizobia inoculant.

\section{Educational level}

Educational level was found to have positive influence on the intensity of inoculant uptake with a coefficient of 0.291 . This implies that when a farmer educational status increases by one unit, the probability that a farmer uses soybean inoculant increase by 0.291 keeping all things constant. This result confirms Lavison, ${ }^{8}$ assertion that education of the farmer has have a positive influence on farmers' decision to adopt new technology. Through, increasing their ability to obtain; process and use information relevant to adoption of the new technology.

\section{Farming experience}

Farming experience was found to have negative influence on the intensity of inoculant uptake with a coefficient of -.172. This implies that when a farmer educational status decrease by one year, the probability that a farmer uses soybean inoculant decrease by -.172 keeping all things constant. According to Mignouna et al. ${ }^{10}$ older farmers are assumed to have gained knowledge and experience over time and are better able to evaluate technology information than younger farmers as well as making decision on adoption.

\section{Radio program}

The use radio to access information on rhizobia inoculant was found to have positive influence on the intensity of inoculant uptake with a coefficient of 0.270 . This implies that when a farmers is expose to information on rhizobia inoculant increase by one unit, the probability that a farmer uses soybean inoculant increase by 0.270 keeping all things constant

\section{Video show}

The use video to access information on rhizobia inoculant was found to have negative influence on the intensity of inoculant uptake with a coefficient of -.363 . This implies that when a farmers is expose to information on rhizobia inoculant decrease by one unit, the probability that a farmer uses soybean inoculant decrease by -.363 keeping all things constant

\section{Demonstration plot}

The use demonstration to access information on rhizobia inoculant was found to have positive influence on the intensity of inoculant uptake with a coefficient of 0.122 . This implies that when a farmers is expose to information on rhizobia inoculant increase by one unit, the probability that a farmer uses soybean inoculant increase by 0.122 keeping all things constant

\section{Years of inoculant introduction}

The years of inoculant introduction to farmers was found to have negative influence on the intensity of inoculant uptake with a coefficient of -.225 . This implies that when years of inoculant introduction to farmers decrease by one year, the probability that a farmer uses soybean inoculant decrease by -.225 keeping all things constant

From the analysis above, nine variables out of ten variables namely; Sex, Age, Marital Status, Educational level, Farming Experience, Radio Program, Video Show, Demonstration plot and Years of inoculant introduction had a joint influence on the dependent variable (Table 4). ${ }^{13-15}$ 
Table 4 Relationship between Farmers Uptake Rhizobia Inoculant and Socio-economic Factors.

\begin{tabular}{|c|c|c|c|c|c|}
\hline \multirow{2}{*}{ Model } & \multicolumn{2}{|c|}{ Unstandardized coefficients } & \multirow{2}{*}{$\begin{array}{l}\text { Standardized coefficients } \\
\text { Beta }\end{array}$} & \multirow{2}{*}{$\mathbf{T}$} & \multirow{2}{*}{ Sig. } \\
\hline & B & Std. error & & & \\
\hline (Constant) & 1.701 & 0.305 & & 5.585 & 0 \\
\hline Sex & 0.271 & 0.067 & 0.233 & 4.044 & 0 \\
\hline Age & 0.176 & 0.044 & 0.309 & 4.02 & 0 \\
\hline Marital Status & -0.11 & 0.033 & -0.205 & -3.335 & 0.001 \\
\hline Educational level & 0.138 & 0.038 & 0.291 & 3.637 & 0 \\
\hline Farming Experience & -0.1 & 0.038 & -0.172 & -2.606 & 0.01 \\
\hline Total farm size & 0.008 & 0.009 & 0.054 & 0.916 & 0.361 \\
\hline Radio Program & 0.166 & 0.043 & 0.27 & 3.822 & 0 \\
\hline Video Show & -0.241 & 0.042 & -0.363 & -5.746 & 0 \\
\hline Demonstration plot & 0.126 & 0.06 & 0.122 & 2.109 & 0.036 \\
\hline Years of inoculant introduction & -0.208 & 0.057 & -0.225 & -3.638 & 0 \\
\hline
\end{tabular}

Source Field Survey Data, 2017

a. Dependent Variable: Uptake of rhizobia inoculant

Number of observation $=210$ Prob. $>.000$ R-Squared $=.38 \mathrm{I}$ Adj. R-Squared $=.350$

\section{Conclusion}

In assessing the factors which assessed the influence of socioeconomic factors on uptake of rhizobia inoculant technology in the Northern Region. The study results that, there were more males than females farmers in the Northern Region of Ghana. Majority of them are in their middle ages and married. Most farmers had significant experience in farming due to the numbers of years there having. Majority of farmers had no formal education. However, the overall socio-economic factors of farmers have a strong influence on farmer uptake of rhizobia inoculant. However, farm size has no influence on farmer uptake of rhizobia inoculant and for that matter. Farmers with large farm size are generally not in support of rhizobia inoculant usage as this characteristic has no influence on uptake of rhizobia inoculant. Though, years of inoculant introduction to farmers, sex, demonstration plot, age, video show, marital status, farm size, farming experience, radio program and educational level have influence on uptake of rhizobia inoculant. This suggests that focusing on these farmers socio-economic characteristic would aid in realising widescale usage of rhizobia inoculant among farmers.

\section{Acknowledgements}

None.

\section{Conflict of interest}

Authors declare that there is no conflict of interest.

\section{References}

1. Sanginga N, PL Woomer. Integrated soil fertility management in africa: principles, practices and developmental process. tropical soil biology and fertility institute of the international centre for tropical agriculture. Nairobi; 2009.

2. Tairo EV, Ndakidemi PA. Macronutrients uptake in soybean as affected by bradyrhizobium japonicum inoculation and phosphorus (p) supplements. American Journal of Plant Science. 2014;5:488-496.

3. Giller KE. Nitrogen fixation in tropical cropping systems. 2nd ed. CAB International, Wallingford, UK; 2001.

4. IITA. Soybean overview. Summary. 5pp. Information Age; 2009.

5. Paynel F, Lesuffleur F, Bigot J, et al. A study of ${ }^{15} \mathrm{~N}$ transfer between legumes and grasses. Agron Sustain Dev. 2008;28(2);281-290.

6. Bala A, NK Karanja, M Murwira. Production and use of rhizobial inoculants in Africa. 2011.

7. Dogbe W, Etwire PM, Martey E, et al. Economics of soybean production: evidence from saboba and chereponi districts of northern region of ghana. Journal of Agricultural Research. 2013;5:1-12.

8. Lavison, R. Factors influencing the adoption of organic fertilizers in vegetable production in accra, Msc Thesis, Accra Ghana; 2013.

9. Fernandez CJ, Daberkow S, Huang H. The adoption of IPM techniques by vegetable growers in Florida, Michigan and Texas. Journal of Agricultural and Applied Economics. 1994;26(1):158-172.

10. Mignouna B, Manyong M, Rusike J, et al. Determinants of AdoptingImazapyr-Resistant Maize Technology and its Impact on Household Income in Western Kenya. In: Hall B \& Khan B. 2002. AgBioforum. 2011;14(3):158-163.

11. Kannaiyan S. Nitrogen contribution by azolla to rice crop. Proc Indian Natl Sci. Acad Part B Biol Sci. 1993;59:309-314. 
12. Bonabana WJ. (2002. Assessing factors affecting adoption of agricultural technologies: the case of integrated pest management (IPM) in Kum District, Msc. Thesis Eastern Uganda; 2002.

13. Carletto C, A Kirk, P Winters. Non-traditional exports, traditional constraints: The adoption and diffusion of cash crops among smallholders in Guatemala; 2007.
14. MoFA. Ghana annual report of agricultural growth in Ghana; 2012.

15. Oster E, R Thornton. Determinants of technology adoption: Private value and peer effects in menstrual cup take-up mimeo university of Chicago; 2009 . 